\title{
A Model of Party Discipline in Congress*
}

\author{
Galina Zudenkova ${ }^{\dagger}$ \\ Department of Economics and CREIP, Universitat Rovira i Virgili
}

\begin{abstract}
This paper studies the impacts of party discipline on allocation of scarce federal resources among national districts. In particular, I model the distribution of government spending within a two-party legislature as an asymmetric contest game between congress members, in which the majority party has a relative advantage in directing pork barrel into its partisan districts. The party leaders can enforce discipline in their corresponding parties to make their congress members support the party line, i.e., maximize the party's total share of pork barrel (rather than follow interests of their home districts). I show that if the relative advantage of the majority party in allocating government spending is not very high then in equilibrium, both leaders choose to impose discipline in their corresponding parties. Under party discipline, a per district pork-barrel share of the majority party decreases, while that of the minority party increases, relative to the allocation with no party discipline. My results therefore indicate that party discipline favors the minority party and leads to less biased distribution of government spending among national districts.
\end{abstract}

JEL classification: D72, H41.

Keywords: Party discipline; Majority party; Minority party; Pork-barrel spending.

${ }^{*}$ The author thanks Daron Acemoglu, Micael Castanheira, Luis Corchón, Benoît Crutzen, Torun Dewan, Daniel Diermeier, Simon Hix, Philippos Louis, Margherita Negri, and seminar and conference participants at several institutions for helpful comments and suggestions. Project grant ECO2008-02738 from the Spanish Ministry of Science and Innovation and grant 2011LINE-01 from Universitat Rovira i Virgili and Banco Santander are gratefully acknowledged. The usual disclaimer applies.

${ }^{\dagger}$ Department of Economics and CREIP, Universitat Rovira i Virgili, Av. de la Universitat 1, Reus 43204, Spain. E-mail address: galina.zudenkova@gmail.com. 


\section{Introduction}

In modern democracies, party discipline is defined as the ability of the leadership of a party to control its members in the legislature. Party discipline usually refers to the ability of a party leader to get his party's congress members to support the party line rather than to follow the special interests of their home districts. Party discipline has been a topic of frequent study in the empirical literature (see Heller and Mershon 2008, Krehbiel 2000, McCarty et al. 2001, Rohde 1991, and Snyder and Groseclose 2000, among many others).

A number of authors have produced formal models of party discipline. For example, some researchers have elaborated on informational arguments, pointing out that strong party discipline informs voters about the future policy of a candidate who, once elected, cannot deviate from the party's official platform (Ashworth and Bueno de Mesquita 2004, Castanheira and Crutzen 2010, Cox and McCubbins 1993, Snyder and Ting 2002). In a similar vein, Grossman and Helpman (2008) defined party discipline as a party's ability to induce ex-post adherence to a preannounced position. In other words, the level of party discipline determines the "extent of commitment to party platforms." ${ }^{1}$ In some other studies, party discipline has been modeled as the ability of the party leadership to control its members in the legislature such that they vote in line with the party's ideological position (Colomer 2005, Eguia 2011, Iaryczower 2008, McGillivray 1997, Patty 2008, Volden and Bergman 2006). In these models, the party leaders' objective is to discipline party members who might have different ideological preferences. Diermeier and Feddersen (1998a, 1998b) provided an institutional explanation for cohesive voting of legislators in parliamentary systems. They showed that the vote-of-confidence procedure common in parliamentary democracies creates an incentive for cohesion in voting.

While a number of studies have identified and formally analyzed party discipline, there remains a great deal of uncertainty with regard to the impacts of party discipline on policy outcomes. $^{2}$ The present paper contributes to this line. In particular, I address the following question. How does party discipline in the congress affect the distribution of government spending among national districts? I refer here to the distribution of pork-barrel spending in

\footnotetext{
${ }^{1}$ Grossman and Helpman (2008), p. 330.

${ }^{2}$ An exception is Grossman and Helpman (2008) who studied how differences in party discipline affect local public goods spending. In their setting, however, party discipline is modeled as an exogenously given institutional variable-an "extent of commitment to party platforms." They found a non-monotonic relationship between this institutional variable and pork-barrel spending. The present paper in turn adopts a standard definition of party discipline as the ability of party leaders to induce members to support the party line. Moreover, it endogenizes party discipline by modeling explicitly the party leaders' problem.
} 
a two-party legislature within the presidential system.

I model allocation of scarce government spending in the congress as a contest between congress members. Congress members want to bring pork barrel into their home district. To do so, each congress member expends a costly effort. Think of this as an effort needed to introduce and amend a bill that benefits a congress member's home district or to filibuster a bill that favors other districts. A higher effort increases a pork-barrel share a congress member brings home, and decreases that of other congress members. I assume that a congress member affiliated with the majority party finds it easier to bring pork-barrel spending into her home district than does her counterpart affiliated with the minority party. This assumption aims to reflect the fact that the majority party has a relative advantage in allocating spending to its partisan districts owing to certain features of legislative process (such that a simple majority is needed to pass a bill, and the majority party leadership decides when to place a bill on the calendar for consideration). As a result, with no party discipline, a congress member affiliated with the majority party exerts a higher effort and brings more pork barrel into her home district than does her counterpart affiliated with the minority party. The distribution of pork barrel is therefore biased in favor of the majority party.

Party leaders (i.e., the majority leader and the minority leader) care about the total share of government spending directed into partisan districts of their corresponding parties. There is therefore a conflict of interests between a representative congress member and her party leadership. Indeed, each congress member cares only about her own share of pork barrel while the party leadership promotes the party line, i.e., maximizes the party's total share of pork barrel. The goal of a party leader is to make his party's members take into account how their actions affect the party line. So the party leaders can impose a certain type of control, known as party discipline, on their congress members to make them support the party line rather than follow the special interests of their home districts. A level of party discipline determines the strength with which a congress member shares the preferences of her party leadership, i.e., maximizes not only her own share of pork barrel but also the party's total share. Under party discipline, a congress member thus faces a certain trade-off. She has an extra incentive to expend effort to increase her own pork-barrel share and therefore the total pork-barrel share of her party. At the same time, an extra effort decreases a share of pork barrel directed into the districts of other members affiliated with the same party, which demotivates the congress member. I show that the former effect prevails such that the congress members' efforts increase with a level of discipline in their corresponding parties. As a result, a congress member's share of pork barrel increases with a level of discipline in her own party but decreases with a level of discipline in the rival party. 
The party leaders simultaneously choose discipline levels in their corresponding parties to promote the party lines. If the minority party has a sufficient number of seats in the congress and the relative advantage of the majority party in allocating government spending is not very high then both party leaders impose positive discipline levels in their corresponding parties. The minority leader has more stake in enforcing party discipline than does the majority leader since with no party discipline, a per district spending share of the majority party exceeds that of the minority party. It follows that in equilibrium, a discipline level of the minority party is higher than that of the majority party and, as a result, the minority party congress members exert higher effort than do their counterparts affiliated with the majority party. The minority party members might even get a higher per district share of government spending than do the members of the majority party. This happens if the relative advantage of the majority party in allocating government spending is sufficiently low. However, the majority party always gets a greater total share of pork barrel than does the minority party.

My results indicate that party discipline in the congress somewhat smooths distribution of government spending. Indeed, after imposing party discipline, a per district pork-barrel share of the majority party decreases, while that of the minority party increases, relative to the allocation with no party discipline. Introduction of party discipline in the congress therefore favors the minority party and results in less inequitable distribution of pork-barrel spending among the national districts.

The results of this paper are related to the literature on inter-group contests (see Katz et al. 1990, Baik 1993, Riaz et al. 1995, Esteban and Ray 2001, among many others). This literature studies externalities, which emerge if the contest prize is a public good for a welldefined group of recipients. In my framework, the party's total share of government spending has indeed a public good nature under party discipline. In contrast with the literature on inter-group contests, I further develop the model by introducing group leaders who impose group objectives on their members.

The rest of the paper is organized as follows. Section 2 outlines a model. Section 3 presents the formal analysis. Finally, Section 4 concludes the paper.

\section{Model}

Consider a congress that forms the legislative branch of government in a society with a twoparty system. The congress is composed of a certain number of congress members, one for each of the national districts. Each congress member is affiliated with one of the two political parties. A party that holds a majority in the legislature will be referred to as the majority 
party and denoted by $m a j$, while the other party will be referred to as the minority party and denoted by min. Denote by $n_{m a j}$ and $n_{\text {min }}$ the numbers of congress members affiliated with the majority and minority parties, respectively, where $n_{m a j}>n_{m i n}$ and $n_{m a j}+n_{m i n}$ is the number of members of the congress. ${ }^{3}$

The congress is assumed to perform a purely distributive task of allocating government spending into $n_{m a j}+n_{m i n}$ national districts. ${ }^{4}$ Distributive policies (often referred to as pork barrel) are those, which benefit only the districts in which the spending occurs. The size of the government spending is normalized to 1 . To bring spending (i.e., pork barrel) into her home district, each congress member $i$ exerts an effort $a_{i} \geq 0, i=1, \ldots, n_{\operatorname{maj}}+n_{\min }$. Think of this as an effort needed to introduce and amend a bill that benefits congress member $i$ 's home district or to filibuster a bill that favors other districts. The cost of the effort of congress member $i$ is $C\left(a_{i}\right)=a_{i}{ }^{5}$

The legislative process consists of several steps. ${ }^{6}$ A bill is first introduced to the congress (by any congress member). It is then referred to the appropriate committee or subcommittee (where it may be accepted, amended, or rejected entirely). In case of approval by the committee, the bill is reported to the floor of the congress, and the majority party leadership decides when to place it on the calendar for consideration. When the bill comes up for consideration in the congress, debate starts where each congress member may introduce amendments or filibuster it. ${ }^{7}$ Once debate is over, the vote of a simple majority passes the bill. $^{8}$ In the context of the distributive policies model under consideration, this legislative procedure suggests two things.

1. First, government spending to district $i$, denoted by $s_{i} \in[0,1]$, increases with effort $a_{i}$

\footnotetext{
${ }^{3}$ In the analysis, I will mention the results for the case in which the parties have equal number of seats in the congress.

${ }^{4}$ Thus, the model ignores other important powers of the congress such as the powers to lay and collect taxes and imposts, to pay the debts, to provide the defense and general welfare of the society, etc. The analysis of those is left for future research.

${ }^{5}$ The qualitative results of the model hold for a convex cost function. A linear cost function $C\left(a_{i}\right)=a_{i}$ is introduced in order to simplify the algebra.

${ }^{6}$ I refer here to the legislative process of the United States Congress not specifying particular differences between the procedures in the House of Representatives and the Senate but rather describing the legislative steps common for both chambers. The details can be found at http://www.whitehouse.gov/ourgovernment/legislative-branch.

${ }^{7}$ A filibuster (common in the US Senate) is a procedure by which a Senator delays a vote on a bill-and by extension its passage-by refusing to stand down.

${ }^{8} \mathrm{I}$ assume here that once the bill passes the congress, it becomes law. In reality, the bill is then sent to the President who may approve it or veto it and send it back to the congress.
} 
congress member $i$ exerts to bring pork barrel into her home district, and decreases with effort of all the other congress members $a_{j}, j=1, \ldots, n_{m a j}+n_{m i n}, j \neq i$. Intuitively, the higher the effort a congress member makes introducing and amending a desired bill or the lower the effort other congress members make filibustering this bill, the more likely the bill passes the congress leading to higher levels of pork-barrel spending in the district. Moreover, higher efforts of other congress members imply more pork-barrel spending in their home districts and therefore (owing to the nature of a zero-sum game under consideration) less spending in the district of interest.

2. Second, the legislative process is somewhat biased in favor of the majority party. On the one hand, it is the leadership of the majority party (not of the minority party) who decides when to place a bill for consideration in the congress. Some bills may wait for months or never be scheduled at all. On the other hand, a simple majority is needed to pass a bill. Therefore, if agreed on a bill, congress members of the majority party can pass it. However, even if agreed, congress members of the minority party do not form a simple majority and therefore cannot pass a bill. This implies that, ceteris paribus, a congress member affiliated with the majority party, maj, finds it easier to bring pork-barrel spending into her home district than does her counterpart affiliated with the minority party, min.

I then model spending allocation in the congress with the Tullock contest success function (1980) such that government spending to district $i, s_{i}$, becomes

$$
s_{i}\left(a_{1}, \ldots, a_{n_{m a j}+n_{m i n}}\right)= \begin{cases}\frac{\beta_{i} a_{i}}{\sum_{j=1}^{n_{m a j}+n_{m i n}} \beta_{j} a_{j}} & \text { if } \max \left\{a_{1}, \ldots, a_{n_{m a j}+n_{m i n}}\right\}>0, \\ \frac{1}{n_{m a j}+n_{m i n}} & \text { otherwise }\end{cases}
$$

where

$$
\beta_{i}= \begin{cases}\beta & \text { if } i \text { is affiliated with the majority party } \operatorname{maj} \\ 1 & \text { if } i \text { is affiliated with the minority party min }\end{cases}
$$

with $\beta>1$. Parameter $\beta$ reflects the relative advantage of the majority party in allocating spending to the partisan districts and the restriction $\beta>1$ captures the idea that the legislative process somewhat favors the majority party.

\subsection{Congress Members and Party Leaders}

I assume that each congress member wants to bring pork barrel into her home district and therefore chooses effort level $a_{i}$ to maximize

$$
s_{i}\left(a_{1}, \ldots, a_{n_{m a j}+n_{m i n}}\right)-C\left(a_{i}\right) .
$$


The stated preferences might arise owing to the connection between pork barreling and reelection (for empirical evidence of this connection, see, for example, Alvarez and Saving 1997, and Stein and Bickers 1994). An office-motivated congress member then tries hard to bring pork-barrel spending into her home district to please voters and gain reelection. Alternatively, a congress member might care about the interests of her constituency and therefore wants to direct government spending into her home district rather than to neighboring districts.

Each party has a party leader. I refer to the leader of the majority party as majority leader, and to the leader of the minority party as minority leader. Each party leader is assumed to care about the total share of government spending directed into the party's partisan districts. These preferences might reflect two situations. First, a party leader seeks to maximize the reelection chances of the party's incumbent politicians (like in Fréchette et al. 2008). Then, owing to the connection between pork barreling and reelection, he directs government spending into the partisan districts in order to please voters and thus to increase reelection prospects of the party's incumbent congress members. Second, a party leader might care about the voters, which support the party, and wants to distribute government spending in their favor. Whatever is the interpretation, a party leader's objective is to maximize the aggregate spending coming to the party's partisan districts. I refer to this objective as a party line. Therefore, the majority party line is to maximize

$$
\sum_{i \in m a j} s_{i}\left(a_{1}, \ldots, a_{n_{m a j}+n_{m i n}}\right)
$$

while the minority party line is to maximize

$$
\sum_{i \in \min } s_{i}\left(a_{1}, \ldots, a_{n_{m a j}+n_{m i n}}\right)
$$

where $i \in \operatorname{maj}$ and $i \in \min$ mean that congress member $i$ is affiliated with the majority party and minority party, respectively.

The party leaders can impose a certain type of control, known as party discipline, on their congress members. In modern democracies, party discipline usually refers to the ability of a party leader to get his party's congress members to support the party line rather than to follow the special interests of their home districts. In the context of the distributive policies model under consideration, party discipline is the ability of a party leader to make his party's members take into account how their actions (i.e., an effort to bring home the bacon) affect aggregate spending directed into the party's partisan districts. Assume now that the party leaders can ensure party discipline by imposing the party's objective (i.e., the party line) on their party's congress members. In particular, a party leader $k \in\{\operatorname{maj}, \min \}$ can impose 
a level of party discipline $\lambda_{k} \geq 0$ to get his party's congress member to support the party line (i.e., to care about a share of government spending directed into the party's partisan districts). This level of party discipline $\lambda_{k}$ determines the strength with which a congress member shares the preferences of her party leadership. Thus, it follows that the congress member $i$ 's net objective function becomes

$$
\begin{aligned}
& s_{i}\left(a_{1}, \ldots, a_{n_{m a j}+n_{m i n}}\right)+\lambda_{m a j} \sum_{j \in m a j} s_{j}\left(a_{1}, \ldots, a_{n_{m a j}+n_{m i n}}\right)-C\left(a_{i}\right) \text { if } i \in \text { maj }, \\
& s_{i}\left(a_{1}, \ldots, a_{n_{m a j}+n_{m i n}}\right)+\lambda_{m i n} \sum_{j \in m i n} s_{j}\left(a_{1}, \ldots, a_{n_{m a j}+n_{m i n}}\right)-C\left(a_{i}\right) \text { if } i \in \text { min. }
\end{aligned}
$$

Party discipline is costly to enforce: a party leader bears a cost $c\left(\lambda_{k}\right)=\lambda_{k}$ of imposing a level of party discipline $\lambda_{k} \cdot{ }^{9}$ Think of this as a cost of convincing party members to coordinate their efforts and keep united in order to maximize a total share of government spending directed into the party's partisan districts. Therefore, the net objective of the majority leader is

$$
\sum_{i \in m a j} s_{i}\left(a_{1}, \ldots, a_{n_{m a j}+n_{m i n}}\right)-c\left(\lambda_{m a j}\right)
$$

while that of the minority leader is

$$
\sum_{i \in \min } s_{i}\left(a_{1}, \ldots, a_{n_{m a j}+n_{m i n}}\right)-c\left(\lambda_{\min }\right) .
$$

Note that the party leaders' incentives are negatively aligned: the majority leader maximizes a share of spending going to his partisan districts while the minority leader maximizes its complement, i.e., a share of spending going to all the other districts. However, owing to the party discipline, there is an intra-party alignment of incentives: a congress member cares not only about her home district's interests (i.e., a share of pork-barrel spending in her home district) but also about the party line (a share of pork-barrel spending in the districts of all congress members affiliated with the same political party).

\subsection{Timing}

The timing of events is as follows. First, the majority leader and the minority leader impose levels of party discipline $\lambda_{m a j}$ and $\lambda_{m i n}$, respectively. The congress members then exert efforts $a_{i}, i=1, \ldots, n_{m a j}+n_{m i n}$, which determine a share of pork-barrel spending $s_{i}$ in each national district.

The game is analyzed backwards to solve for a subgame perfect equilibrium. The congress members' efforts $a_{i}$ are found first. Next, I examine the party leaders' choice of party discipline levels $\lambda_{m a j}$ and $\lambda_{m i n}$.

\footnotetext{
${ }^{9}$ The qualitative results of the model hold for a convex cost function. A linear cost function $c\left(\lambda_{k}\right)=\lambda_{k}$ is introduced in order to simplify the algebra.
} 


\section{Analysis}

Consider first the congress members' decisions about the efforts $a_{i}$ when the levels of party discipline in the majority party and minority party are $\lambda_{m a j} \geq 0$ and $\lambda_{\min } \geq 0$, respectively. ${ }^{10}$ A congress member affiliated with the majority party, $i \in m a j$, chooses an effort $a_{i}$ to maximize

$$
\begin{aligned}
s_{i}\left(a_{1}, \ldots, a_{n_{m a j}+n_{m i n}}\right)+\lambda_{m a j} \sum_{j \in m a j} s_{j}\left(a_{1}, \ldots, a_{n_{m a j}+n_{m i n}}\right) & -C\left(a_{i}\right)= \\
& \frac{\beta\left(a_{i}+\lambda_{m a j} \sum_{j \in m a j} a_{j}\right)}{\sum_{j \in m a j} \beta a_{j}+\sum_{j \in \text { min }} a_{j}}-a_{i} .
\end{aligned}
$$

A congress member affiliated with the minority party, $i \in \min$, chooses an effort $a_{i}$ to maximize

$$
\begin{aligned}
s_{i}\left(a_{1}, \ldots, a_{n_{m a j}+n_{m i n}}\right)+\lambda_{\min } \sum_{j \in \min } s_{j}\left(a_{1}, \ldots, a_{n_{m a j}+n_{m i n}}\right) & -C\left(a_{i}\right)= \\
& \frac{a_{i}+\lambda_{\min } \sum_{j \in \text { min }} a_{j}}{\sum_{j \in \text { maj }} \beta a_{j}+\sum_{j \in \text { min }} a_{j}}-a_{i} .
\end{aligned}
$$

The congress members' maximization problem is analyzed in the Appendix. Note that owing to the symmetry of the problem, congress members affiliated with the same political party will exert the same level of effort. In what follows, $a_{m a j}$ will denote an effort of a congress member affiliated with the majority party, $i \in \operatorname{maj}$, while $a_{m i n}$ will denote an effort of a congress member affiliated with the minority party, $i \in$ min. The following proposition establishes results for the congress members' efforts $a_{m a j}\left(\lambda_{m a j}, \lambda_{m i n}\right)$ and $a_{m i n}\left(\lambda_{m a j}, \lambda_{m i n}\right)$ when the levels of party discipline are $\lambda_{m a j}$ and $\lambda_{m i n}$. (Proofs of this and other propositions are given in the Appendix. ${ }^{11}$ )

Proposition 1. Given the levels of party discipline $\lambda_{m a j}$ and $\lambda_{m i n}$, the congress members' equilibrium efforts are equal to

$$
a_{m a j}\left(\lambda_{m a j}, \lambda_{m i n}\right)=\left\{\begin{array}{cl}
\frac{1}{\beta}\left(\left(1+\lambda_{m a j}\right) \beta n_{m i n}-\left(n_{m i n}-1\right)\right) \Lambda & \text { if } \beta<\frac{\left(1+\lambda_{m i n}\right) n_{m a j}}{n_{m a j}-1}, \\
\frac{n_{m a j}-1}{n_{m a j}^{2}} & \text { otherwise, }
\end{array}\right.
$$

\footnotetext{
${ }^{10}$ Obviously, $a_{i}=0$ for $\forall i=1, \ldots, n_{m a j}+n_{m i n}$, is not an equilibrium. Indeed, each congress member would like to deviate and exert a tiny effort $\varepsilon>0$ to get the entire spending in her home district.

${ }^{11}$ The results for the case in which the parties have equal number of seats in the congress $\left(n_{\operatorname{maj}}=n_{\min }=n\right)$ and the legislative process does not favor any party $(\beta=1)$ are also presented in the Appendix.
} 


$$
a_{\text {min }}\left(\lambda_{\text {maj }}, \lambda_{\text {min }}\right)=\left\{\begin{array}{cl}
\left(\left(1+\lambda_{\text {min }}\right) n_{m a j}-\beta\left(n_{m a j}-1\right)\right) \Lambda & \text { if } \beta<\frac{\left(1+\lambda_{m i n}\right) n_{m a j}}{n_{m a j}-1}, \\
0 & \text { otherwise }
\end{array}\right.
$$

where

$\Lambda=\frac{\left(1+\lambda_{m i n}\right) n_{m a j}\left(\left(1+\lambda_{m a j}\right) \beta n_{m i n}-\left(n_{m i n}-1\right)\right)+\left(n_{m i n}-1\right)\left(\left(1+\lambda_{m i n}\right) n_{m a j}-\beta\left(n_{m a j}-1\right)\right)}{\left(n_{m a j}\left(\left(1+\lambda_{m a j}\right) \beta n_{m i n}-\left(n_{m i n}-1\right)\right)+n_{m i n}\left(\left(1+\lambda_{m i n}\right) n_{m a j}-\beta\left(n_{m a j}-1\right)\right)\right)^{2}}$.

The corresponding shares of government spending $s_{m a j}\left(\lambda_{m a j}, \lambda_{m i n}\right)$ and $s_{m i n}\left(\lambda_{m a j}, \lambda_{m i n}\right)$ are equal to

$$
\begin{aligned}
& s_{\text {maj }}\left(\lambda_{\text {maj }}, \lambda_{\text {min }}\right)=\left\{\begin{array}{cl}
\frac{1}{\Delta}\left(\left(1+\lambda_{\text {maj }}\right) \beta n_{\text {min }}-\left(n_{\text {min }}-1\right)\right) & \text { if } \beta<\frac{\left(1+\lambda_{m i n}\right) n_{m a j}}{n_{m a j}-1}, \\
\frac{1}{n_{m a j}} & \text { otherwise, }
\end{array}\right. \\
& s_{\text {min }}\left(\lambda_{\text {maj }}, \lambda_{\text {min }}\right)=\left\{\begin{array}{cl}
\frac{1}{\Delta}\left(\left(1+\lambda_{\text {min }}\right) n_{m a j}-\beta\left(n_{m a j}-1\right)\right) & \text { if } \beta<\frac{\left(1+\lambda_{m i n}\right) n_{m a j}}{n_{m a j}-1}, \\
0 & \text { otherwise, }
\end{array}\right.
\end{aligned}
$$

where

$$
\Delta=n_{m a j}\left(\left(1+\lambda_{m a j}\right) \beta n_{m i n}-\left(n_{m i n}-1\right)\right)+n_{m i n}\left(\left(1+\lambda_{m i n}\right) n_{m a j}-\beta\left(n_{m a j}-1\right)\right) .
$$

Note that a congress member affiliated with the minority party exerts effort and therefore brings pork barrel into her home district only if the relative advantage of the majority party in allocating government spending is not very high (formally, $\beta<\frac{\left(1+\lambda_{\min }\right) n_{\operatorname{maj}}}{n_{m a j}-1}$ ). Indeed, if bringing pork barrel is much easier for a congress member affiliated with the majority party than for that affiliated with the minority party then the latter might find it optimal to make no effort rather than to bear a cost of it in exchange for a tiny share of government spending.

Supporting the party line (i.e., maximizing the aggregate spending going to the party's partisan districts) implies a certain trade-off for a congress member. On the one hand, an extra effort will increase her own share of pork barrel and decrease a share of spending going to the districts of congress members affiliated with the rival party. On the other hand, this same effort will also decrease a share of pork barrel directed into the districts of other members affiliated with the same party. The former effect motivates a congress member to exert effort while the latter effect discourages her from doing so. The former effect dominates, however, since the congress members' efforts increase with a level of discipline in their corresponding parties:

$$
\frac{\partial a_{m a j}\left(\lambda_{m a j}, \lambda_{m i n}\right)}{\partial \lambda_{m a j}}>0, \quad \frac{\partial a_{m i n}\left(\lambda_{m a j}, \lambda_{m i n}\right)}{\partial \lambda_{\min }}>0
$$


for $\beta<\frac{\left(1+\lambda_{m i n}\right) n_{m a j}}{n_{m a j}-1}$. In other words, the more a congress member cares about the party line (i.e., about the aggregate spending going to the party's partisan districts), the more incentives she has and therefore the higher effort she exerts. As a result, a congress member's share of pork barrel increases with a level of discipline in her own party but decreases with a level of discipline in the rival party:

$$
\begin{aligned}
& \frac{\partial s_{m a j}\left(\lambda_{m a j}, \lambda_{m i n}\right)}{\partial \lambda_{m a j}}>0, \quad \frac{\partial s_{m a j}\left(\lambda_{m a j}, \lambda_{m i n}\right)}{\partial \lambda_{m i n}}<0, \\
& \frac{\partial s_{\text {min }}\left(\lambda_{m a j}, \lambda_{m i n}\right)}{\partial \lambda_{\min }}>0, \quad \frac{\partial s_{\text {min }}\left(\lambda_{m a j}, \lambda_{m i n}\right)}{\partial \lambda_{m a j}}<0
\end{aligned}
$$

for $\beta<\frac{\left(1+\lambda_{m i n}\right) n_{m a j}}{n_{m a j}-1}$.

How do the pork-barrel shares $s_{m a j}\left(\lambda_{m a j}, \lambda_{m i n}\right)$ and $s_{m i n}\left(\lambda_{m a j}, \lambda_{m i n}\right)$ depend on the values of the parameters? If the relative advantage of the majority party in allocating government spending is not very high (formally, $\beta<\frac{\left(1+\lambda_{m i n}\right) n_{m a j}}{n_{m a j}-1}$ ) then a higher degree of it increases the pork-barrel share of a congress member affiliated with the majority party but has an opposite effect on a congress member affiliated with the minority party:

$$
\frac{\partial s_{m a j}\left(\lambda_{m a j}, \lambda_{m i n}\right)}{\partial \beta}>0, \quad \frac{\partial s_{m i n}\left(\lambda_{m a j}, \lambda_{m i n}\right)}{\partial \beta}<0 .
$$

The more members there are in the congress (the greater $n_{m a j}$ or $n_{\min }$ is), the more demands for distributive policies there are for a fixed size of total spending and therefore per district spending decreases:

$$
\begin{aligned}
\frac{\partial s_{m a j}\left(\lambda_{m a j}, \lambda_{m i n}\right)}{\partial n_{m a j}}<0, & \frac{\partial s_{m a j}\left(\lambda_{m a j}, \lambda_{m i n}\right)}{\partial n_{m i n}}<0, \\
\frac{\partial s_{m i n}\left(\lambda_{m a j}, \lambda_{m i n}\right)}{\partial n_{m a j}} & <0, \quad \frac{\partial s_{m i n}\left(\lambda_{m a j}, \lambda_{m i n}\right)}{\partial n_{m i n}}<0 .
\end{aligned}
$$

Note, however, that the relationships between the congress members' efforts $a_{m a j}\left(\lambda_{m a j}, \lambda_{m i n}\right)$, $a_{m i n}\left(\lambda_{m a j}, \lambda_{\text {min }}\right)$ and parameters $\beta, n_{m a j}, n_{m i n}$ are not monotonic.

Consider the case with no party discipline as a benchmark, $\lambda_{m a j}=\lambda_{m i n}=0$. I denote by $a_{m a j}^{0}$ and $a_{m i n}^{0}$ the congress members' efforts and by $s_{m a j}^{0}$ and $s_{m i n}^{0}$ the corresponding shares of government spending in this case. Plugging $\lambda_{m a j}=\lambda_{\min }=0$ in the expressions in Proposition 1 yields

$$
\begin{aligned}
& a_{m a j}^{0}=\left\{\begin{array}{cl}
\frac{\left(n_{m a j}+n_{m i n}-1\right)\left(1+n_{m i n}(\beta-1)\right)}{\left(n_{m a j}+n_{m i n} \beta\right)^{2}} & \text { if } \beta<\frac{n_{m a j}}{n_{m a j}-1}, \\
\frac{n_{m a j}-1}{n_{m a j}^{2}} & \text { otherwise, }
\end{array}\right. \\
& a_{m i n}^{0}=\left\{\begin{array}{cc}
\frac{\beta\left(n_{m a j}+n_{m i n}-1\right)\left(\beta-n_{m a j}(\beta-1)\right)}{\left(n_{m a j}+n_{m i n} \beta\right)^{2}} & \text { if } \beta<\frac{n_{m a j}}{n_{m a j}-1}, \\
0 & \text { otherwise, }
\end{array}\right.
\end{aligned}
$$




$$
\begin{aligned}
& s_{m a j}^{0}=\left\{\begin{array}{cl}
\frac{1+n_{m i n}(\beta-1)}{n_{m a j}+n_{m i n} \beta} & \text { if } \beta<\frac{n_{m a j}}{n_{m a j}-1}, \\
\frac{1}{n_{m a j}} & \text { otherwise, }
\end{array}\right. \\
& s_{m i n}^{0}=\left\{\begin{array}{cl}
\frac{\beta-n_{m a j}(\beta-1)}{n_{m a j}+n_{m i n} \beta} & \text { if } \beta<\frac{n_{m a j}}{n_{m a j}-1}, \\
0 & \text { otherwise. }
\end{array}\right.
\end{aligned}
$$

With no party discipline, a congress member affiliated with the majority party exerts a higher effort and brings more pork barrel into her home district than does her counterpart affiliated with the minority party, $a_{m a j}^{0}>a_{m i n}^{0}$ and $s_{m a j}^{0}>s_{m i n}^{0}$. Intuitively, since the legislative process is somewhat biased in favor of the majority party and each congress member cares only about her own share of pork-barrel spending, a congress member affiliated with the majority party finds it easier to bring pork-barrel spending into her home district than does her counterpart affiliated with the minority party and therefore makes a higher effort and gets a greater per district share of government spending. ${ }^{12}$ These results are in line with empirical literature on the allocation of federal resources, which provides evidence on majority party advantage in distribution of legislative pork (see, for example, Balla et al. 2002).

I turn now to the party leaders' choice of party discipline levels $\lambda_{m a j}$ and $\lambda_{m i n}$. A party leader's objective is to maximize the total share of government spending directed into his party's partisan districts net of costs of imposing party discipline. The objective of the majority leader becomes

$$
\begin{aligned}
& \sum_{i \in m a j} s_{i}\left(a_{1}, \ldots, a_{n_{m a j}+n_{m i n}}\right)-c\left(\lambda_{m a j}\right)= \\
& \left\{\begin{array}{cl}
\frac{n_{m a j}}{\Delta}\left(\left(1+\lambda_{m a j}\right) \beta n_{m i n}-\left(n_{m i n}-1\right)\right)-\lambda_{m a j} & \text { if } \beta<\frac{\left(1+\lambda_{m i n}\right) n_{m a j}}{n_{m a j}-1}, \\
1-\lambda_{m a j} & \text { otherwise, }
\end{array}\right.
\end{aligned}
$$

while that of the minority leader becomes

$$
\begin{aligned}
& \sum_{i \in \text { min }} s_{i}\left(a_{1}, \ldots, a_{n_{m a j}+n_{m i n}}\right)-c\left(\lambda_{\text {min }}\right)= \\
&\left\{\begin{array}{cl}
\frac{n_{m i n}}{\Delta}\left(\left(1+\lambda_{m i n}\right) n_{m a j}-\beta\left(n_{m a j}-1\right)\right)-\lambda_{m i n} & \text { if } \beta<\frac{\left(1+\lambda_{m i n}\right) n_{m a j}}{n_{m a j}-1}, \\
-\lambda_{\min } & \text { otherwise, }
\end{array}\right.
\end{aligned}
$$

\footnotetext{
${ }^{12}$ With no party discipline, the relationships between the congress members' efforts $a_{m a j}^{0}, a_{m i n}^{0}$ and parameters $\beta, n_{m a j}, n_{m i n}$ become monotonic. A higher $\beta$ increases an effort of a congress member affiliated with the majority party but decreases that of a congress member affiliated with the minority party: $\frac{\partial a_{m a j}^{0}}{\partial \beta}>0$, $\frac{\partial a_{\min }^{0}}{\partial \beta}<0$. The more members there are in the congress (the greater $n_{\text {maj }}$ or $n_{\min }$ is), the lower the congress members' efforts: $\frac{\partial a_{m a j}^{0}}{\partial n_{m a j}}<0, \frac{\partial a_{m a j}^{0}}{\partial n_{m i n}}<0, \frac{\partial a_{m i n}^{0}}{\partial n_{m a j}}<0, \frac{\partial a_{m i n}^{0}}{\partial n_{m i n}}<0$.
} 
where $\Delta$ is given in Proposition 1 . The party leaders simultaneously choose discipline levels in their corresponding parties. The leaders' maximization problem is analyzed in the Appendix in the proof of Proposition 2. ${ }^{13}$ I show that in equilibrium, there are positive levels of discipline imposed in both parties if the condition $\frac{n_{\min }-1}{n_{\min }} \frac{1}{\beta}-\frac{1+\beta+\beta^{2}}{(1+\beta)^{2}}>0$ holds (which is simplified to $n_{\min }>\frac{(1+\beta)^{2}}{1+\beta-\beta^{3}}$ where $\left.1+\beta-\beta^{3}>0\right)$. Otherwise, depending on the values of parameters $\beta, n_{\min }$ and $n_{\text {maj }}$, either the minority leader imposes a positive level of discipline in his party while the majority leader enforces no discipline, or both party leaders impose no discipline in their corresponding parties. (The details for these cases are given in the Appendix.) In what follows, I restrict the space of parameter values to satisfy the condition $n_{\min }>\frac{(1+\beta)^{2}}{1+\beta-\beta^{3}}$ where $1+\beta-\beta^{3}>0$ and concentrate the analysis on the situation with positive discipline levels in both political parties. ${ }^{14}$ The results are summarized in the following proposition.

Proposition 2. If the minority party has a sufficient number of seats in the congress and the relative advantage of the majority party in allocating government spending is not very high (formally, $n_{\text {min }}>\frac{(1+\beta)^{2}}{1+\beta-\beta^{3}}$ where $1+\beta-\beta^{3}>0$ ) then there is a unique equilibrium $\lambda_{\text {maj }}^{*}$, $\lambda_{\min }^{*}$ given by

$$
\begin{aligned}
\lambda_{m a j}^{*} & =\frac{n_{m i n}-1}{n_{m i n}} \frac{1}{\beta}-\frac{1+\beta+\beta^{2}}{(1+\beta)^{2}}, \\
\lambda_{m i n}^{*} & =\frac{n_{m a j}-1}{n_{m a j}} \beta-\frac{1+\beta+\beta^{2}}{(1+\beta)^{2}} .
\end{aligned}
$$

The congress members' equilibrium efforts $a_{m a j}^{*}, a_{m i n}^{*}$ and the corresponding shares of government spending $s_{m a j}^{*}, s_{\text {min }}^{*}$ are equal to

$$
\begin{aligned}
a_{\text {maj }}^{*} & =\frac{n_{\text {maj }} n_{\text {min }}\left(1+\beta+\beta^{2}\right)^{2}-\left(n_{\text {maj }}+\beta^{2} n_{m i n}\right)(1+\beta)^{2}}{n_{\text {maj }}^{2} n_{\text {min }}(1+\beta)^{4}}, \\
a_{\text {min }}^{*} & =\frac{n_{\text {maj }} n_{\text {min }}\left(1+\beta+\beta^{2}\right)^{2}-\left(n_{\text {maj }}+\beta^{2} n_{m i n}\right)(1+\beta)^{2}}{n_{m a j} n_{m i n}^{2}(1+\beta)^{4}}, \\
s_{\text {maj }}^{*} & =\frac{\beta}{n_{\text {maj }}(1+\beta)}, \\
s_{\text {min }}^{*} & =\frac{1}{n_{\text {min }}(1+\beta)} .
\end{aligned}
$$

\footnotetext{
${ }^{13}$ The results for the case in which the parties have equal number of seats in the congress $\left(n_{\operatorname{maj}}=n_{\text {min }}=n\right)$ and the legislative process does not favor any party $(\beta=1)$ are also presented in the Appendix.

${ }^{14}$ The detailed analysis for parameter values, which do not satisfy the condition $n_{\min }>\frac{(1+\beta)^{2}}{1+\beta-\beta^{3}}$ where $1+\beta-\beta^{3}>0$, is available upon request.
} 
This is an equilibrium with positive discipline levels in both parties: $\lambda_{m a j}^{*}>0, \lambda_{\min }^{*}>0$. Moreover, a discipline level of the minority party is higher than that of the majority party, $\lambda_{m i n}^{*}>\lambda_{m a j}^{*}$, and the minority party congress members exert higher effort than do the majority party congress members, $a_{m i n}^{*}>a_{m a j}^{*}>0$. However, a total share of government spending directed into the majority party partisan districts exceeds that directed into the minority party districts, $n_{m a j} s_{m a j}^{*}>n_{m i n} s_{m i n}^{*}$. As for the spending per district $\left(s_{m a j}^{*}\right.$ versus $\left.s_{\text {min }}^{*}\right)$, the result depends on the parameter values. If $\beta>\frac{n_{m a j}}{n_{m i n}}$ then $s_{\text {maj }}^{*}>s_{\text {min }}^{*}$. Otherwise, $s_{\text {maj }}^{*} \leq s_{\text {min }}^{*}$.

The intuition for these results is as follows. Owing to the fact that the legislative process is somewhat biased in favor of the majority party, with no party discipline a per district porkbarrel share of the majority party exceeds that of the minority party. It follows then that the minority leader has more stake in imposing party discipline than does the majority leader. ${ }^{15}$ Moreover, as was mentioned above, each congress member faces a trade-off between her own interests and those of her party leadership. Note that this trade-off is more pronounced for a congress member affiliated with the majority party since she has more members from her own party to care about and less rivals from the minority party to compete with for pork barrel. It follows that if the relative advantage of the majority party in allocating government spending is not very high, then given the same level of party discipline, a congress member affiliated with the majority party has less incentive to exert effort than does her counterpart affiliated with the minority party. This, together with the fact that the minority leader has more in stake than does the majority leader, implies that the marginal benefit of imposing discipline is greater in the minority party than in the majority party. It follows then that in equilibrium, a level of discipline is higher in the minority party than in the majority party, $\lambda_{m i n}^{*}>\lambda_{m a j}^{*}$. The members of the minority party exert more effort and might even get a higher per district share of government spending than do the members of the majority party. (The latter happens if $\beta<\frac{n_{m a j}}{n_{\min }}$ ). However, a total share of government spending of the majority party exceeds that of the minority party by the magnitude of the majority party relative advantage $\beta$ in allocating government spending: $\frac{n_{m a j} s_{m a j}^{*}}{n_{m i n} s_{m i n}^{*}}=\beta$.

How do the equilibrium discipline levels depend on the values of the parameters? First, a larger relative advantage $\beta$ of the majority party in allocating government spending decreases

\footnotetext{
${ }^{15}$ In other words, owing to the fact that the party share of pork barrel is concave in the discipline level, the "disadvantaged" minority party gains more than "advantaged" majority party from the same increment of a discipline level.
} 
a discipline level of the majority party but increases that of the minority party:

$$
\frac{\partial \lambda_{m a j}^{*}}{\partial \beta}<0, \quad \frac{\partial \lambda_{\min }^{*}}{\partial \beta}>0
$$

Intuitively, the more the legislative process favors the majority party (the higher $\beta$ is), the more pork barrel the majority party gets. Therefore, more stake the minority leader has and less stake the majority leader has in imposing discipline in their corresponding parties. Second, an equilibrium discipline level increases with the number of seats the rival party holds in the congress:

$$
\frac{\partial \lambda_{m a j}^{*}}{\partial n_{\min }}>0, \quad \frac{\partial \lambda_{m i n}^{*}}{\partial n_{m a j}}>0 .
$$

Indeed, the more numerous the party, the greater its share of government spending. This strengthens the incentives of the other party leader to enforce discipline in his party.

According to my results, party discipline in the congress favors the minority party and leads to less inequitable distribution of government spending. Indeed, after imposing party discipline, a per district pork-barrel share of the majority party decreases, while that of the minority party increases, relative to the allocation with no party discipline:

$$
s_{m a j}^{*}<s_{m a j}^{0}, \quad s_{m i n}^{*}>s_{m i n}^{0} .
$$

The congress members affiliated with the minority party exert higher effort under party discipline:

$$
a_{\text {min }}^{*}>a_{m i n}^{0}
$$

As for equilibrium efforts of the congress members affiliated with the majority party, the answer is ambiguous and depends on parameter values. One can check that if the minority party holds just a few seats less than does the majority party, then $a_{m a j}^{*}>a_{m a j}^{0}$. However, if the majority party has supermajority (i.e., the difference in the number of seats hold by the majority and minority parties is sufficiently large) then $a_{m a j}^{*}<a_{m a j}^{0} \cdot{ }^{16}$

\section{Conclusions}

This paper has analyzed the impacts of party discipline on allocation of distributive policies within a two-party legislature. I model the distribution of pork-barrel spending in the congress as an asymmetric contest game, in which congress members exert costly effort to bring home the bacon. Moreover, the majority party members find it easier than the minority party members to bring pork barrel into their home districts. It follows then that with no party

\footnotetext{
${ }^{16}$ The formal details are available upon request.
} 
discipline, the majority party members expend higher effort and get a greater per district share of government spending than do the minority party members. The distribution of pork barrel is therefore biased in favor of the majority party.

The party leaders' can impose discipline in their corresponding parties to make their members support the party objective, i.e., maximize the party's total share of pork barrel (rather than follow interests of their home districts). My results indicate that if the minority party has a sufficient number of seats in the congress and the relative advantage of the majority party in allocating government spending is not very high then in equilibrium, both leaders decide to impose discipline in their corresponding parties. Moreover, a discipline level of the minority party is higher than that of the majority party. As a result, the minority party members exert more effort and might even get a higher per district share of government spending than do the members of the majority party. The latter happens if the relative advantage of the majority party in allocating government spending is sufficiently low. Party discipline therefore favors the minority party, which gets a greater per district share of pork barrel relative to the allocation with no party discipline. I conclude thus that party discipline leads to less biased distribution of federal resources among national districts.

Even though the model is very stylized, it yields a number of empirically testable predictions. First, according to my results, a per district pork-barrel share is increasing in the strength of discipline in the corresponding party and decreasing in the strength of discipline in the rival party. Second, the model predictions indicate that the minority leader imposes stronger discipline on his party's congress members than does the majority leader. Finally, a total share of government spending of the majority party exceeds that of the minority party regardless of the strength of discipline in both parties. Testing these predictions implies identifying and measuring party discipline. This might be a hard but feasible task, and has been addressed to some extent by a number of authors (see the references to empirical studies of party discipline in the Introduction). 


\section{Appendix}

\section{A. Congress Members' Maximization problem and Proof of Proposition 1}

Consider first the maximization problem of a congress member affiliated with the majority party, $i \in$ maj. The first-order condition with respect to effort $a_{i}$ is

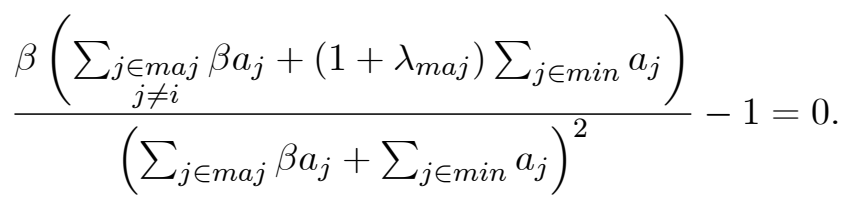

The second-order condition is satisfied:

$$
-\frac{2 \beta^{2}\left(\sum_{\substack{j \in \text { maj } \\ j \neq i}} \beta a_{j}+\left(1+\lambda_{m a j}\right) \sum_{j \in \min } a_{j}\right)}{\left(\sum_{j \in m a j} \beta a_{j}+\sum_{j \in \text { min }} a_{j}\right)^{3}}<0 .
$$

Consider now the maximization problem of a congress member affiliated with the minority party, $i \in \min$. The first-order condition with respect to effort $a_{i}$ is

$$
\frac{\left(1+\lambda_{\min }\right) \sum_{j \in \text { maj }} \beta a_{j}+\sum_{\substack{j \in \text { min } \\ j \neq i}} a_{j}}{\left(\sum_{j \in \text { maj }} \beta a_{j}+\sum_{j \in \text { min }} a_{j}\right)^{2}}-1=0 .
$$

The second-order condition is satisfied:

$$
-\frac{2\left(\left(1+\lambda_{\text {min }}\right) \sum_{j \in \operatorname{maj}} \beta a_{j}+\sum_{\substack{j \in \text { min } \\ j \neq i}} a_{j}\right)}{\left(\sum_{j \in \text { maj }} \beta a_{j}+\sum_{j \in \min } a_{j}\right)^{3}}<0 .
$$

It is straightforward to check that, owing to the symmetry of the problem, congress members affiliated with the same political party will exert the same level of effort. I denote by $a_{m a j}$ an effort of a congress member affiliated with the majority party, $i \in m a j$, and by $a_{\min }$ an effort of a congress member affiliated with the minority party, $i \in \min$. The first-order conditions (A.1) and (A.2) then become, respectively,

$$
\begin{aligned}
& \frac{\beta\left(\left(n_{m a j}-1\right) \beta a_{m a j}+\left(1+\lambda_{m a j}\right) n_{m i n} a_{m i n}\right)}{\left(n_{m a j} \beta a_{m a j}+n_{m i n} a_{m i n}\right)^{2}}-1=0, \\
& \frac{\left(1+\lambda_{m i n}\right) n_{m a j} \beta a_{m a j}+\left(n_{m i n}-1\right) a_{m i n}}{\left(n_{m a j} \beta a_{m a j}+n_{m i n} a_{m i n}\right)^{2}}-1=0 .
\end{aligned}
$$


Solving for efforts $a_{m a j}$ and $a_{m i n}$ yields

$$
\begin{aligned}
& a_{m a j}\left(\lambda_{m a j}, \lambda_{m i n}\right)=\frac{1}{\beta}\left(\left(1+\lambda_{m a j}\right) \beta n_{m i n}-\left(n_{m i n}-1\right)\right) \cdot \\
& \frac{\left(1+\lambda_{m i n}\right) n_{m a j}\left(\left(1+\lambda_{m a j}\right) \beta n_{m i n}-\left(n_{m i n}-1\right)\right)+\left(n_{m i n}-1\right)\left(\left(1+\lambda_{m i n}\right) n_{m a j}-\beta\left(n_{m a j}-1\right)\right)}{\left(n_{m a j}\left(\left(1+\lambda_{m a j}\right) \beta n_{m i n}-\left(n_{m i n}-1\right)\right)+n_{m i n}\left(\left(1+\lambda_{m i n}\right) n_{m a j}-\beta\left(n_{m a j}-1\right)\right)\right)^{2}}, \\
& \frac{\left(1+\lambda_{m i n}\right) n_{m a j}\left(\left(1+\lambda_{m a j}\right) \beta n_{m i n}-\left(n_{m i n}-1\right)\right)+\left(n_{m i n}-1\right)\left(\left(1+\lambda_{m i n}\right) n_{m a j}-\beta\left(n_{m a j}-1\right)\right)}{\left(n_{m a j}\left(\left(1+\lambda_{m a j}\right) \beta n_{m i n}-\left(n_{m i n}-1\right)\right)+n_{m i n}\left(\left(1+\lambda_{m i n}\right) n_{m a j}-\beta\left(n_{m a j}-1\right)\right)\right)^{2}} .
\end{aligned}
$$

One can check that for $\forall \lambda_{m a j} \geq 0, \lambda_{\text {min }} \geq 0, \beta>1$ and $n_{m a j}>n_{\text {min }} \geq 1$, an effort $a_{m a j}\left(\lambda_{m a j}, \lambda_{m i n}\right)$ is strictly positive. However, $a_{m i n}\left(\lambda_{m a j}, \lambda_{m i n}\right)$ is strictly positive only if $\beta<\frac{\left(1+\lambda_{m i n}\right) n_{m a j}}{n_{m a j}-1}$. Otherwise, a congress member affiliated with the minority party exerts zero effort, and the first-order condition (A.1) yields the best response of a congress member from the majority party: $a_{m a j}=\frac{n_{m a j}-1}{n_{m a j}^{2}}$.

A congress member affiliated with the majority party brings home a share $s_{m a j}$ of government spending:

$$
\begin{aligned}
& s_{m a j}\left(\lambda_{m a j}, \lambda_{m i n}\right)=\frac{\beta a_{m a j}}{n_{m a j} \beta a_{m a j}+n_{m i n} a_{m i n}}= \\
& \left\{\begin{array}{cl}
\frac{\left(1+\lambda_{m a j}\right) \beta n_{m i n}-\left(n_{m i n}-1\right)}{n_{m a j}\left(\left(1+\lambda_{m a j}\right) \beta n_{m i n}-\left(n_{m i n}-1\right)\right)+n_{m i n}\left(\left(1+\lambda_{m i n}\right) n_{m a j}-\beta\left(n_{m a j}-1\right)\right)} & \text { if } \beta<\frac{\left(1+\lambda_{m i n}\right) n_{m a j}}{n_{m a j}-1}, \\
\frac{1}{n_{m a j}} & \text { otherwise. }
\end{array}\right.
\end{aligned}
$$

A congress member affiliated with the minority party brings home a share $s_{\min }$ of government spending:

$$
\begin{aligned}
& s_{\text {min }}\left(\lambda_{m a j}, \lambda_{\text {min }}\right)=\frac{a_{\text {min }}}{n_{m a j} \beta a_{m a j}+n_{m i n} a_{m i n}}= \\
& \left\{\begin{array}{cl}
\frac{\left(1+\lambda_{m i n}\right) n_{m a j}-\beta\left(n_{m a j}-1\right)}{\left.n_{m a j}\left(\left(1+\lambda_{m a j}\right) \beta n_{m i n}-\left(n_{m i n}-1\right)\right)+n_{m i n}\left(1+\lambda_{m i n}\right) n_{m a j}-\beta\left(n_{m a j}-1\right)\right)} & \text { if } \beta<\frac{\left(1+\lambda_{m i n}\right) n_{m a j}}{n_{m a j}-1} \\
0 & \text { otherwise. }
\end{array}\right.
\end{aligned}
$$

Finally, note that if the parties have equal number of seats in the congress, i.e., $n_{m a j}=$ $n_{\min }=n$, and the legislative process does not favor any party, i.e., $\beta=1$, then congress members' efforts become

$$
\begin{aligned}
& \left.a_{m a j}\left(\lambda_{m a j}, \lambda_{m i n}\right)\right|_{n_{m a j}=n_{m i n}=n, \beta=1}=\left(\lambda_{m a j} n+1\right) \frac{\left(1+\lambda_{m i n}\right) n\left(\lambda_{m a j} n+1\right)+(n-1)\left(\lambda_{\text {min }} n+1\right)}{n^{2}\left(n\left(\lambda_{m a j}+\lambda_{m i n}\right)+2\right)^{2}}, \\
& \left.a_{m i n}\left(\lambda_{m a j}, \lambda_{m i n}\right)\right|_{n_{m a j}=n_{m i n}=n, \beta=1}=\left(\lambda_{\min } n+1\right) \frac{\left(1+\lambda_{\min }\right) n\left(\lambda_{\operatorname{maj}} n+1\right)+(n-1)\left(\lambda_{\min } n+1\right)}{n^{2}\left(n\left(\lambda_{m a j}+\lambda_{m i n}\right)+2\right)^{2}} .
\end{aligned}
$$


In turn, the shares of government spending become

$$
\begin{aligned}
& \left.s_{\text {maj }}\left(\lambda_{\text {maj }}, \lambda_{\text {min }}\right)\right|_{n_{\text {maj }}=n_{\text {min }}=n, \beta=1}=\frac{\lambda_{\text {maj }} n+1}{n\left(n\left(\lambda_{\text {maj }}+\lambda_{\text {min }}\right)+2\right)}, \\
& \left.s_{\text {min }}\left(\lambda_{\text {maj }}, \lambda_{\text {min }}\right)\right|_{n_{m a j}=n_{\text {min }}=n, \beta=1}=\frac{\lambda_{\text {min }} n+1}{n\left(n\left(\lambda_{\text {maj }}+\lambda_{\text {min }}\right)+2\right)} .
\end{aligned}
$$

\section{B. Proof of Proposition 2}

If $\beta<\frac{\left(1+\lambda_{m i n}\right) n_{m a j}}{n_{m a j}-1}$ the first-order condition of the majority leader maximization problem with respect to $\lambda_{m a j}$ is given by

$$
\frac{\beta n_{m a j} n_{m i n}^{2}\left(\left(1+\lambda_{m i n}\right) n_{m a j}-\beta\left(n_{m a j}-1\right)\right)}{\left(n_{m a j}\left(\left(1+\lambda_{m a j}\right) \beta n_{m i n}-\left(n_{m i n}-1\right)\right)+n_{m i n}\left(\left(1+\lambda_{m i n}\right) n_{m a j}-\beta\left(n_{m a j}-1\right)\right)\right)^{2}}-1=0 .
$$

The second-order condition is satisfied for $\beta<\frac{\left(1+\lambda_{m i n}\right) n_{m a j}}{n_{m a j}-1}$ :

$$
-\frac{2 \beta^{2} n_{m a j}^{2} n_{m i n}^{3}\left(\left(1+\lambda_{m i n}\right) n_{m a j}-\beta\left(n_{m a j}-1\right)\right)}{\left(n_{m a j}\left(\left(1+\lambda_{m a j}\right) \beta n_{m i n}-\left(n_{m i n}-1\right)\right)+n_{m i n}\left(\left(1+\lambda_{m i n}\right) n_{m a j}-\beta\left(n_{m a j}-1\right)\right)\right)^{3}}<0 .
$$

The first-order condition of the minority leader maximization problem with respect to $\lambda_{\min }$ is

$$
\frac{n_{m a j}^{2} n_{m i n}\left(\left(1+\lambda_{m a j}\right) \beta n_{m i n}-\left(n_{m i n}-1\right)\right)}{\left(n_{m a j}\left(\left(1+\lambda_{m a j}\right) \beta n_{m i n}-\left(n_{m i n}-1\right)\right)+n_{m i n}\left(\left(1+\lambda_{m i n}\right) n_{m a j}-\beta\left(n_{m a j}-1\right)\right)\right)^{2}}-1=0 .
$$

The second-order condition holds for $\beta<\frac{\left(1+\lambda_{\min }\right) n_{m a j}}{n_{m a j}-1}$ :

$$
-\frac{2 n_{m a j}^{3} n_{m i n}^{2}\left(\left(1+\lambda_{m a j}\right) \beta n_{m i n}-\left(n_{m i n}-1\right)\right)}{\left(n_{m a j}\left(\left(1+\lambda_{m a j}\right) \beta n_{m i n}-\left(n_{m i n}-1\right)\right)+n_{m i n}\left(\left(1+\lambda_{m i n}\right) n_{m a j}-\beta\left(n_{m a j}-1\right)\right)\right)^{3}}<0 .
$$

Solving (B.1) and (B.2) for $\lambda_{m a j}$ and $\lambda_{m i n}$ yields

$$
\begin{aligned}
& \lambda_{m a j}^{*}=\frac{n_{m i n}-1}{n_{m i n}} \frac{1}{\beta}-\frac{1+\beta+\beta^{2}}{(1+\beta)^{2}}, \\
& \lambda_{\text {min }}^{*}=\frac{n_{m a j}-1}{n_{m a j}} \beta-\frac{1+\beta+\beta^{2}}{(1+\beta)^{2}} .
\end{aligned}
$$

Note that the condition $\beta<\frac{\left(1+\lambda_{m i n}\right) n_{m a j}}{n_{m a j}-1}$ is satisfied for $\lambda_{\min }^{*}$ in (B.3). One can easily show that $\lambda_{m i n}^{*}>\lambda_{m a j}^{*}$. Plugging (B.3) in $a_{m a j}\left(\lambda_{m a j}, \lambda_{m i n}\right), a_{m i n}\left(\lambda_{m a j}, \lambda_{m i n}\right), s_{m a j}\left(\lambda_{m a j}, \lambda_{m i n}\right)$ and $s_{\text {min }}\left(\lambda_{m a j}, \lambda_{\text {min }}\right)$ from Proposition 1 yields the congress members' equilibrium efforts 
$a_{m a j}^{*}, a_{m i n}^{*}$ and the corresponding shares of government spending $s_{m a j}^{*}, s_{\text {min }}^{*}$ :

$$
\begin{aligned}
a_{m a j}^{*} & =\frac{n_{m a j} n_{m i n}\left(1+\beta+\beta^{2}\right)^{2}-\left(n_{m a j}+\beta^{2} n_{m i n}\right)(1+\beta)^{2}}{n_{m a j}^{2} n_{m i n}(1+\beta)^{4}}, \\
a_{m i n}^{*} & =\frac{n_{m a j} n_{m i n}\left(1+\beta+\beta^{2}\right)^{2}-\left(n_{m a j}+\beta^{2} n_{m i n}\right)(1+\beta)^{2}}{n_{m a j} n_{m i n}^{2}(1+\beta)^{4}}, \\
s_{m a j}^{*} & =\frac{\beta}{n_{m a j}(1+\beta)}, \\
s_{m i n}^{*} & =\frac{1}{n_{\text {min }}(1+\beta)} .
\end{aligned}
$$

In what follows, I characterize values of parameters $\beta, n_{m a j}$ and $n_{\min }$ for which party leaders choose to enforce discipline in their corresponding parties.

1. If $\frac{n_{\min }-1}{n_{\min }} \frac{1}{\beta}-\frac{1+\beta+\beta^{2}}{(1+\beta)^{2}}>0$ then both the majority and minority leaders introduce discipline in their corresponding parties. In this case, $\lambda_{m a j}$ and $\lambda_{m i n}$ are given in (B.3).

2. If $\frac{n_{\min }-1}{n_{\min }} \frac{1}{\beta}-\frac{1+\beta+\beta^{2}}{(1+\beta)^{2}} \leq 0<\frac{n_{m a j}-1}{n_{m a j}} \beta-\frac{1+\beta+\beta^{2}}{(1+\beta)^{2}}$ then the majority leader decides not to enforce discipline in the majority party, $\lambda_{m a j}=0$. The discipline level in the minority party can be found by plugging $\lambda_{m a j}=0$ in (B.2) that yields

$$
\lambda_{\text {min }}=\frac{n_{\text {maj }}\left(\sqrt{n_{\min }\left(n_{\min }(\beta-1)+1\right)}-1\right)-n_{\min } \beta}{n_{\text {maj }} n_{\text {min }}} .
$$

To complete this case, one needs to check that $\lambda_{\min }$ in (B.4) is positive and satisfies the condition $\beta<\frac{\left(1+\lambda_{m i n}\right) n_{m a j}}{n_{m a j}-1}$.

3. Finally, if $\frac{n_{m a j}-1}{n_{m a j}} \beta-\frac{1+\beta+\beta^{2}}{(1+\beta)^{2}} \leq 0$, or if $\lambda_{\text {min }}$ in (B.4) is negative or does not satisfy the condition $\beta<\frac{\left(1+\lambda_{\min }\right) n_{m a j}}{n_{m a j}-1}$ the party leaders decide not to enforce discipline in their corresponding parties, i.e., $\lambda_{m a j}=\lambda_{m i n}=0$. This is also the case when $\beta \geq \frac{n_{m a j}}{n_{m a j}-1}$ and total government spending goes to the majority party districts while the minority party districts get no spending.

Finally, note that if the parties have equal number of seats in the congress and the legislative process does not favor any party (i.e., $n_{m a j}=n_{\min }=n$ and $\beta=1$ ), then (B.3) becomes

$$
\left.\lambda_{m a j}\right|_{n_{m a j}=n_{m i n}=n, \beta=1}=\left.\lambda_{m i n}\right|_{n_{m a j}=n_{m i n}=n, \beta=1}=\frac{n-4}{4 n},
$$


which is strictly positive for $n>4$. The congress members' equilibrium efforts and the corresponding shares of government spending are equal to

$$
\begin{aligned}
& \left.a_{m a j}^{*}\right|_{n_{m a j}=n_{m i n}=n, \beta=1}=\left.a_{m i n}^{*}\right|_{n_{m a j}=n_{m i n}=n, \beta=1}=\frac{9 n-8}{16 n^{2}}, \\
& \left.s_{m a j}^{*}\right|_{n_{m a j}=n_{m i n}=n, \beta=1}=\left.s_{m i n}^{*}\right|_{n_{m a j}=n_{m i n}=n, \beta=1}=\frac{1}{2 n} .
\end{aligned}
$$

\section{References}

[1] Alvarez, R. Michael, and Jason L. Saving, 1997. "Deficits, Democrats, and Distributive Benefits: Congressional Elections and the Pork Barrel in the 1980s," Political Research Quarterly, 50, 809-831.

[2] Ashworth, Scott, and Ethan Bueno de Mesquita, 2004. "Endogenous Party Discipline with Variable Electoral and Legislative Institutions," Institute of Governmental Studies Working Paper \# 2004-7.

[3] Baik, Kyung Hwan, 1993. "Effort Levels in Contests: the Public-good Prize Case," Economics Letters, 41, 363-367.

[4] Balla, Steven J., Eric D. Lawrence, Forrest Maltzman, and Lee Sigelman, 2002. "Partisanship, Blame Avoidance, and the Distribution of Legislative Pork," American Journal of Political Science, 46, 515-525.

[5] Castanheira, Micael, and Benoit S. Y. Crutzen, 2010. "Comparative Politics with Endogenous Intra-Party Discipline," mimeo.

[6] Colomer, Josep M., 2005. "Policy Making in Divided Government: A Pivotal Actors Model with Party Discipline," Public Choice, 125, 247-269.

[7] Cox, Gary W, and Mathew D. McCubbins, 1993. Legislative Leviathan. Berkeley: University of California Press.

[8] Diermeier, Daniel, and Timothy J. Feddersen, 1998a. "Cohesion in Legislatures and the Vote of Confidence Procedure," American Political Science Review, 92, 611-621.

[9] Diermeier, Daniel, and Timothy J. Feddersen, 1998b. "Comparing Constitutions: Cohesion and Distribution in Legislatures," European Economic Review, 42, 665-672.

[10] Eguia, Jon X., 2011. "Voting Blocs, Party Discipline and Party Formation," Games and Economic Behavior, 73, 111-135. 
[11] Esteban, Joan, and Debraj Ray, 2001. "Collective Action and the Group Size Paradox," American Political Science Review, 95, 663-672.

[12] Fréchette, Guillaume R., Francois Maniquet, and Massimo Morelli, 2008. "Incumbents' Interests and Gender Quotas," American Journal of Political Science, 52, 891-909.

[13] Grossman, Gene M., and Elhanan Helpman, 2008. "Party Discipline and Pork-Barrel Politics," in E. Helpman, ed., Institutions and Economic Performance. Cambridge: Harvard University Press.

[14] Heller, William B., and Carol Mershon, 2008. "Dealing in Discipline: Party Switching and Legislative Voting in the Italian Chamber of Deputies, 1988-2000," American Journal of Political Science, 52, 910-925.

[15] Iaryczower, Matias, 2008. "Contestable Leadership: Party Leaders as Principals and Agents," Quarterly Journal of Political Science, 3, 203-225.

[16] Katz, Eliakim, Shmuel Nitzan, and Jacob Rosenberg, 1990. "Rent-seeking for Pure Public Goods," Public Choice, 65, 49-60.

[17] Krehbiel, Keith, 2000. "Party Discipline and Measures of Partisanship," American Journal of Political Science, 44, 212-227.

[18] McCarty, Nolan, Keith T. Poole, and Howard Rosenthal, 2001. "The Hunt for Party Discipline in Congress," American Political Science Review, 95, 673-687.

[19] McGillivray, Fiona, 1997. "Party Discipline as a Determinant of the Endogenous Formation of Tariffs," American Journal of Political Science, 41, 584-607.

[20] Patty, John W., 2008. "Equilibrium Party Government," American Journal of Political Science, 52, 636-655.

[21] Riaz, Khalid, Jason F. Shogren, and Stanley R. Johnson, 1995. "A General Model of Rent Seeking for Public Goods," Public Choice, 82, 243-259.

[22] Rohde, David, 1991. Parties and Leaders in the Postreform House. Chicago: University of Chicago Press.

[23] Snyder, James M. Jr., and Tim Groseclose, 2000. "Estimating Party Influence in Congressional Roll-Call Voting," American Journal of Political Science, 44, 193-211. 
[24] Snyder, James M. Jr., and Michael M. Ting, 2002. "An Informational Rationale for Political Parties," American Journal of Political Science, 46, 90-110.

[25] Stein, Robert M., and Kenneth N. Bickers, 1994. "Congressional Elections and the Pork Barrel," Journal of Politics, 56, 377-399.

[26] Tullock, Gordon, 1980. "Efficient Rent Seeking," in James Buchanan, Roger Tollison, and Gordon Tullock, ed., Towards a Theory of the Rent-Seeking Society. Texas A\&M University Press, College Station, Texas.

[27] Volden, Craig, and Elizabeth Bergman, 2006. "How Strong Should Our Party Be? Party Member Preferences Over Party Cohesion," Legislative Studies Quarterly, XXXI, 71-104. 